\title{
UPLC-MS: A Powerful Tool in Analytical Research
}

\author{
Ravindra K Rawal1* and Rohit Bhatia ${ }^{2,3}$ \\ 1Department of Chemistry, Maharishi Markandeshwar (Deemed to be University), India \\ ${ }^{2}$ Department of Pharmaceutical Sciences \& Technology, MRSPTU, India \\ ${ }^{3}$ Department of Pharmaceutical Chemistry, ISF College of Pharmacy, India
}

\section{Editorial \\ Volume 2 Issue 2}

Received Date: July 06, 2018

Published Date: July 11, 2018

*Corresponding author: Ravindra K Rawal, Department of Chemistry, Maharishi Markandeshwar (Deemed to be University), Mullana-133207, Haryana, India, Tel: +91-1731-304287; Email: rawal.ravindra@gmail.com

\section{Editorial}

The emergence of ultra-performance liquid chromatography (UPLC) coupled to mass spectrometry (MS) as an alternative to traditional high-performance liquid chromatography techniques is a powerful technique that combines the physical separation capabilities of liquid chromatography with the mass analysis capabilities of mass spectroscopy with significant gains in resolution and sensitivity and marked reductions in the overall time of analysis [1]. UPLC is an advanced technique which consists of narrow bore columns with very fine packing materials (approximate particle size: $1.7 \mu \mathrm{m})$ and the mobile phases are introduced at ultrahigh pressures [2]. The typical UPLC instrument is designed in such a way that the integrated system from pump (withstand a pressure up to $15000 \mathrm{psi}$ ) to auto sampler, heater, detector, software are fully compatible with the small particle technology [3]. Due to this advancement, ultra-sensitive responses are obtained and ultimately detection sensitivity by MS is enhanced [4]. UPLC- MS technique has tremendous applications in various analytical procedures which include: toxicity analysis, analysis of food stuffs, beverages, identification of drug metabolites in biological samples, for simultaneous extraction and screening of diuretics, betablockers, steroids in human fluids, Functional Genomic Studies and multi-residue analysis of pharmaceuticals in waste water etc.

Cannabinoids are one of the critical forensic investigations worldwide. Therefore an accurate and precise method was reported for detection and quantification of cannabinoids in blood samples utilizing the UPLC-MS technique. Solid phase extraction technique (SPE) was used for extraction of cannabinoids from blood samples. The tetrahydrocannabinol (THC) and its major metabolites were quantified by ultra-high pressure liquid chromatography-tandem mass spectrometry. This method was advantageous over the existing GC-MS method by minimized specimen handling, ease of extraction as well as reduced run time [5].

Folates are important nutritional ingredients which have role in various health benefits such as reduced risk of cardiovascular diseases [6], dementia [7] and cancer [8]. The UPLC-MS technique was successfully utilized for determinations of trace concentrations of folates in rice and ultrasensitive results were obtained such as LOD value of $0.06-0.45 \mu \mathrm{g} / 100 \mathrm{~g}$ and LOQ value of 0.12 $0.91 \mu \mathrm{g} / 100 \mathrm{~g}$. Six types of folates were determined by this technique with high sensitivity and low matrix interferences [9].

Another excellent application of UPLC-MS technique is in the field of metabolic profiling of human and animal tissues. A two-step process was reported for tissue samples which were based on extraction into "aqueous" and "non-aqueous" phases. High efficiency separation was achieved by UPLC and metabolite identification was carried out through MS [10].

Tibolone is employed as a substitute in place of lack of estrogen production in post-menopausal women due to its estrogenic effects on vagina, bones and thermoregulatory centres of brain. A novel, fast, robust and precise method was developed for the separation and quantification of $3 \alpha$-hydroxy tibolone bioavailability of its formulations in humans by utilizing UPLC-MS technology. The analyte extraction was carried out through liquidliquid extraction from plasma [11]. This method was a landmark in explaining various pharmacokinetic as well as bioequivalence parameters for tibolone as well as for other drugs. 


\section{Medicinal \& Analytical Chemistry International Journal}

Deficiency of B-vitamins in food leads various disorders especially in breast feeding mothers. Therefore a suitable concentration of these vitamins must be present in human milk so as to protect the infant against various diseases [12,13]. A novel, significant, accurate and precise method was reported for rapid, simultaneous analysis of thiamine, riboflavin, Flavin adenine dinucleotide, nicotinamide and pyridoxal in human milk by UPLC -MS technique. The LOQ values obtained were in the range of $0.05-5 \mathrm{ppb}$ with excellent retention time of 2 minutes. Due to presence of endogenous vitamins in milk, a matrix-like calibration curve was used for quantification [14].

Opiate drugs are well known for their therapeutic potentials as well as they are also recognized as substances of abuse. To carry out analysis of opiates, heroin and their metabolites in urine a novel, accurate and robust method was developed by utilizing UPLC-MS technology. The results obtained were highly sensitive which include LOD value in the range $0.001-0.02 \mu \mathrm{g} / \mathrm{ml}$ and LOQ values of $0.003-0.06 \mu \mathrm{g} / \mathrm{ml}$. These methods have been continuously used by National Institute of Public Health (NIPH) since 2007 in routine analysis of opiates [15].

The identification of biomarkers in case of diseases and toxicity is nowadays an advantageous approach in the new drug development. By keeping in view this concept, UPLC-MS approach was utilized to generate molecular fragment information for structural elucidation of biomarkers in biological fluids. This approach has produced both precursor and product ion peaks in a single analytical run. Unlike the traditional techniques, the first quadrupole is not used in this for mass filtration and the data gives exact mass values for precursor and product [16].

Pesticides are routinely used in agriculture field to improve the productivity, still their presence in environment and food stuffs is considered hazardous. A novel UPLC-MS method was developed for multi-residue pesticide analysis in food stuffs. Analysis of 17 polar pesticides samples was carried out in crude apple extract. The result obtained was more sensitive than the traditional HPLC method [17].

Nowadays due to increased industrialization, water resources are continuously contaminated by various pharmaceutical effluents and waste products. A novel and rapid method was developed for analysis of ecologically relevant pharmaceuticals in waste water and surface water using solid phase extraction and UPLC-MS. The results obtained were highly sensitive such as recovery rates from $80-125 \%$ and LOD values of $1.0-51.0 \mathrm{ng} / \mathrm{L}$. This method was significant for monitoring of effluents and surface water samples and from the data presence of many API's was found [18].

Phenolic acids are secondary metabolites obtained from plant resources and are derived from cinnamic and benzoic acids. A novel method has been developed for qualitative and quantitative analysis of 17 phenolic acids in different beverages by utilizing UPLC-MS technique. The analytes were determined by multiple reactions monitoring to obtain highly sensitive results. This method was successively used further for analysis of white wine samples, grapefruit juice and green tea infusion. This method was used for monitoring of 12 phenolic acids in the concentration range of 40.8-9046 $\mu \mathrm{g} / \mathrm{L}$ [19].

So in nut shell, the UPLC-MS technique have been widely adopted in various analytical procedures which involve minute concentration determinations or sensitive materials due to its fast detection time and small particle size technology.

\section{References}

1. Apollonio LG, Pianca DJ, Whitall IR, Maher WA, Kyd JM (2006) A demonstration of the use of ultraperformance liquid chromatography-mass spectrometry [UPLC/MS] in the determination of amphetamine-type substances and ketamine for forensic and toxicological analysis. J Chromatogr B 836(1-2): 111-115.

2. Yu K, Little D, Plumb R, Smith B (2006) Highthroughput quantification for a drug mixture in rat plasma - a comparison of Ultra PerformanceTM liquid chromatography/tandem mass spectrometry with high-performance liquid chromatography/tandem mass spectrometry. Rapid Commun Mass Spectrom 20(4): 544-552.

3. Waters Corporation application note (2004). 720000820EN AG-UL.

4. Waters White Paper (2004) Ultra Performance LC UPLC: New Boundaries for the Chromatography Laboratory, 720000819EN.

5. House CJ, Lyttle C, Blanchard C (2017) An ultra-highpressure liquid chromatography tandem mass 


\section{Medicinal \& Analytical Chemistry International Journal}

spectrometry (UPLC-MS/MS) method for the detection of cannabinoids in whole blood using solid phase extraction. Canadian Socie Forens Sci 50(3): 103-113.

6. Quinlivan EP, McPartlin J, McNulty H, Ward M, Strain JJ, et al. (2002) Importance of both folic acid and vitamin B12 in reduction of risk of vascular disease. Lancet 359 (9302): 227-228.

7. Snowdon DA, Tully CL, Smith CD, Riley KP, Markesbery WR (2000) Serum folate and the severity of atrophy of the neocortex in Alzheimer disease: findings from the Nun study. Am J Clin Nutr 71(4): 993-998.

8. Choi SW, Udelson JE, Ruthazer R, Beshansky JR, Selker HP (2000) Does symptom onset in the morning help predict the diagnosis of acute cardiac ischemia?. J Am Coll Cardiol 35: 405A.

9. Brouwer V, Storozhenko S, Stove CP, Van Daele J, Van Der Straten D, et al. (2010) Ultra-performance liquid chromatography-tandem mass spectrometry(UPLCMS/MS) for the sensitive determination of folates in rice. J Chromat B 878(3-4): 509-513.

10. Want EJ, Masson P, Michopolous F, Wilson ID, Theodoridis G, et al. (2013) Global metabolic profiling of animal and human tissues via UPLC-MS. Nature America 8(1): 17-32.

11. Shinde PV, Pudage A, Jangid A, Mistri H, Patel PK (2013) Application of UPLC-MS/MS for separation and quantification of $3 \alpha$-Hydroxy Tibolone and comparative bioavailability of two Tibolone formulations in healthy volunteers. J Pharm Anal 3(4): 270-277.

12. Allen AH (1994) Maternal micronutrient malnutrition: effects on breast milk and infant nutrition, and priorities for intervention. SCN News 11: 21-24.

13. Spies T0, Cooper C, Blankenhorn MA (1938) The use of nicotinic acid in the treatment of pellagra. J Med Assoc 110(9): 622-627.

14. Hampel D, York ER, Allen LH (2012) Ultraperformance liquid chromatography tandem massspectrometry (UPLC-MS/MS) for the rapid, simultaneous analysis of thiamin, riboflavin, Flavin dinucleotide, nicotinamide and pyridoxal in human milk. J Chromat B 903: 7-13.

15. Berg T, Ludanes E, Christophersen AS, Strand DH (2009) Determination of opiates and cocaine in urine by high $\mathrm{pH}$ mobile phase reversed phase UPLCMS/MS. J Chromat B 877(4): 421-432.

16. Plumb RS, Johnson KA, Rainville P, Smith BW, Wilson ID, et al. (2006) UPLC/MSE; a new approach for generating molecular fragment information for biomarker structure elucidation. Rapid Commun Mass Spectrom 20(13): 1989-1994.

17. Kovalczuck T, Jech M, Pouska J, Hajslova J (2006) Ultra-performance liquid chromatography-tandem mass spectrometry: A novel challenge in multiresidue pesticide analysis in food. Analytica Chimica Acta 577(1): 8-17.

18. Batt AL, Kostich MS, Lazorchak JM (2008) Analysis of ecologically relevant pharmaceuticals in wastewater and surface water using selective solid-phase extraction and UPLC-MS/MS. Anal Chem 80(13): 5021-5030.

19. Gruj J, Novak O, Strnad M (2008) Rapid analysis of phenolic acids in bevarages by UPLC-MS/MS. Food Chemistry 111(3): 789-794.

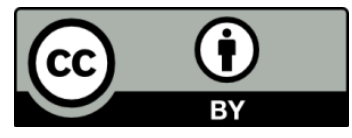

